of an acute medical bed. Thus there is a chain reaction: acute medical receiving beds are blocked because the acute medical beds to which patients should be transferred are blocked by patients who should be in geriatric beds; but these are blocked because there are too few local authority beds to receive patients discharged from geriatric wards.

The acute medical ward is unable to offer its highly specialised and expensive resources to the appropriate patients because a third of its beds are occupied by patients no longer in need of medical care. As Rosenfeld et al have said, this type of hospital will only operate to "the best advantage of the sick, the payment agency and the community at large if both admission and length of stay are based on the patients' needs for service which cannot be rendered as well in other types of institutions, out patient clinics, general practitioner's surgery, or at home."4
CM and JCW are supported by grants from the Scottish Home and Health Department and the Nuffield Provincial Hospitals Trust respectively. We thank Dr R L Richards, Dr G C Timbury, and Dr D N Ross for their comments.

\section{References}

1 Sutherland, A, Scottish Health Service Studies, 1972, 22, 25.

2 Sumner, G, and Smith, R C, Planning Local Authority Services for the Elderly. London, Allen and Unwin, 1970.

${ }^{3}$ Richards, R L, Timbury, G C, and Ross, D N, personal communication, 1975.

${ }^{4}$ Rosenfeld, L S, Goldman, F, and Kaptrio, L A, fournal of Chronic Diseases, 1957, 6, 141.

\title{
Ambulatory electrocardiographic records in patients with transient cerebral attacks or palpitation
}

\author{
A D GOLDBERG, E B RAFTERY, P M M CASHMAN
}

British Medical fournal, 1975, 4, 569-571

\section{Summary}

Continuous electrocardiographic (ECG) records were made over 24 hours in 130 ambulant outpatients complaining of syncope, dizzy turns, or palpitation. In all these patients resting ECGs had failed to show significant dysrhythmias. Exercise testing was performed on 64 patients and also failed to reveal any dysrhythmias. Analysis of the tape recordings, however, showed appreciable dysrhythmias in $74 \%$ of the group. In most cases the dysrhythmias were complex mixtures of rapid supraventricular and ventricular rhythms. Bouts of ventricular tachycardia were seen in seven patients, all of whom were women. Episodic complete heart block was seen in only two patients, but prolonged ventricular gaps (greater than $1.5 \mathrm{~s}$ ), not associated with ectopic beats, were found in 26. No episodes of ventricular fibrillation were recorded.

We conclude that many patients with vague symptoms suggestive of transient cerebral ischaemia or irregular heart action have significant and often dangerous dysrhythmias which can be diagnosed only by long-term recording of the ECG under fully ambulant conditions.

\section{Introduction}

Episodes of transient cerebral ischaemia presenting with ill-

Cardiac Department and the Division of Bioengineering, Northwick Park Hospital and Clinical Research Centre, Harrow, Middx

A D GOLDBERG, MB, MRCP, honorary senior registrar

E B RAFTERY, MD, MRCP, consultant cardiologist

P M M CASHMAN, B Sc, scientific staff, Medical Research Council defined symptoms such as "dizzy turns" are a common reason for hospital outpatient referral. Many of these patients have no obvious abnormal physical signs and are often labelled as sufferıng from cerebral arterıosclerosis. Similarly, many patients are referred with "palpitations" and are thought to be neurotic when examination shows no abnormality. Transient cardiac dysrhythmias could account for the symptoms in both groups. McAllen and Marshall ${ }^{1}$ studied several patients with transient ischaemic attacks who were found to have episodes of complete heart block which accounted for their symptoms. Other workers $^{2-4}$ have shown that accurate heart rhythm analysis requires continuous recordings over long periods in ambulant conditions. We have used the method of long-term electrocardiographic (ECG) recording to study a group of patients presenting with ill-defined symptoms of cerebral ischaemia or palpitation to determine the frequency and nature of cardiac dysrhythmias which might have contributed to their symptoms.

\section{Patients and methods}

We studied 130 patients who were referred to a general medical outpatient clinic. All were complaining of one or more of the following symptoms: palpitation, dizzy attacks, faints, or blackouts (syncope). A full examination was performed in the clinic with an $x$-ray film of the chest and a 12-lead ECG. The ECG included 30-40 beats and a 10-beat record of lead 2. Sixty-four of these patients were exercised for five minutes on a bicycle ergometer with continuous ECG monitoring. The 12-lead ECG was repeated at the end of this test and again five minutes later. These procedures failed to show any serious dysrhythmias and a 24-hour recording was performed on an outpatient basis.

\section{RECORDING TECHNIQUE}

The Medilog cassette recorder was used with a single channel for ECG. ${ }^{5}$ The electrodes were applied in the V1 and V5 positions to give an ECG configuration similar to V5. The tape recorder was light, 
portable, and did not interfere with normal movements. After checking the ECG signal with an oscilloscope the patients were sent about their daily activities for the $\mathbf{2 4}$ hours of the recording. The tapes were analysed with the aid of a purpose-built dysrhythmia detector ${ }^{45}$ (Oxford Instruments Ltd). This unit incorporates a memory oscilloscope to display detected abnormalities, and all dysrhythmias were written out on standard ECG paper for formal analysis. The replay time for a 24-hour tape was 30 minutes if no dysrhythmias were detected. In 84 patients the recordings were repeated either consecutively or at intervals to determine the frequency of dysrhythmias and the increased yield of information from taping for more than 24 hours (table I).

TABLE I-Duration of recording period

\begin{tabular}{l|r|r|r|r|r|r|r}
\hline No of days: & 1 & 2 & 3 & 4 & 7 & 8 & 9 \\
No of patients: & 46 & 40 & 36 & 5 & 1 & 1 & 1 \\
\hline
\end{tabular}

\section{CLASSIFICATION OF PATIENT SYMPTOMS}

These patients complained of symptoms which were vague and ill-defined, but we defined "syncope" as an episode or episodes of loss of consciousness without the clinical characteristics of epilepsy; "dizzy turns" as attacks of dizziness, feelings of faintness, or weakness without loss of consciousness; and "palpitations" as an awareness of the heart beating rapidly, heavily, or irregularly.

The patients were grouped under these headings in order of importance, syncope counting as the most important and palpitations as the least (table II). Patients who complained of dizzy turns and episodes of loss of consciousness were classified as "syncope," but no attempt was made to analyse mixtures of the three symptom groups.

TABLE II-Presenting symptoms

\begin{tabular}{|c|c|c|c|c|c|}
\hline \multicolumn{3}{|c|}{ Symptoms } & $\begin{array}{c}\text { No of } \\
\text { men }\end{array}$ & $\begin{array}{c}\text { No of } \\
\text { women }\end{array}$ & Total \\
\hline $\begin{array}{l}\text { Palpitation } \\
\text { Dizzy turns } \\
\text { Syncope }\end{array}$ & $\begin{array}{l}\cdots \\
\cdots \\
\cdots\end{array}$ & $\because$ & $\begin{array}{r}18 \\
8 \\
22\end{array}$ & $\begin{array}{l}30 \\
21 \\
31\end{array}$ & $\begin{array}{l}48 \\
29 \\
53\end{array}$ \\
\hline \multicolumn{3}{|c|}{ Total } & 48 & 82 & 130 \\
\hline
\end{tabular}

\section{TAPE ANALYSIS}

Isolated ventricular and atrial ectopic beats were observed and printed out, but no detailed counts were made. These dysrhythmias were considered appreciable if the tapes showed one or more episodes with a frequency greater than 1 ectopic beat in 5 sinus beats for at least one minute. Tachycardia (supraventricular or ventricular) was considered to be present if there were one or more episodes of three or more consecutive ectopic beats.

"Ventricular gaps" were defined when there were one or more episodes of ventricular standstill lasting more than 1.5 seconds in the absence of ectopic beats.

\section{Results}

The 48 men and 82 women ranged in age from 16 to 82 years (mean 58.4). The recording period ranged from one to nine days (table I). The numbers and sex distribution in each group are shown in table II. The 12-lead ECG was normal in 68 patients (table III), and in 27 showed changes associated with ischaemia or left ventricula hypertrophy. The remaining 35 patients showed dysrhythmias such as isolated atrial or ventricular ectopic beats, which were not thought to be serious enough to account for the symptoms. Of the 64 patients

TABLE III-Clinic 12-lead ECG analysis

\begin{tabular}{l|c|c|c|c}
\hline \multicolumn{1}{c|}{ ECG } & Palpitations & Dizzy turns & Syncope & Total \\
\hline Normal & 28 & 18 & 22 & 68 \\
Ischaemia & 8 & 5 & 14 & 27 \\
Suggestive dysrhythmias & 12 & 6 & 17 & 35 \\
\hline \multicolumn{1}{c|}{ Total } & 48 & 29 & 53 & 130 \\
\hline
\end{tabular}

who were exercised 57 showed no dysrhythmias and seven showed only isolated ventricular and atrial ectopic beats.

In 16 patients the tape recordings showed no dysrhythmias. Fortyeight patients exhibited atrial dysrhythmias alone, 16 patients had ventricular dysrhythmias alone, and 48 had both atrial and ventricular dysrhythmias. Two patients had episodes of complete heart block without ventricular escape (table IV; fig 1 ). Seven patients had episodes of ventricular tachycardia and five of these presented with palpitation alone (fig 2). All were women aged 43-70. Analysis of the physical signs and resting ECGs failed to show anything which might have been considered suspicious in these patients. Four of the tapes showed ventricular extrasystoles and the other three had atrial extrasystoles alone.

TABLE IV-Dysrhythmias seen on continuous ECG tape recodings

\begin{tabular}{|c|c|c|c|c|}
\hline Tape analysis & Palpitations & Dizzy turns & Syncope & Total \\
\hline \multirow{2}{*}{$\begin{array}{l}\text { Normal } \\
\text { Atrial dysrhythmias } \\
\text { Ventricular dysrhythmias } \\
\text { Atrial and ventricular } \\
\text { dysrhythmias } \\
\text { Third degree heart block }\end{array}$} & $\begin{array}{r}7 \\
19 \\
4\end{array}$ & $\begin{array}{r}3 \\
14 \\
2\end{array}$ & $\begin{array}{r}6 \\
15 \\
10\end{array}$ & $\begin{array}{l}16 \\
48 \\
16\end{array}$ \\
\hline & 18 & $\begin{array}{l}9 \\
1\end{array}$ & $\begin{array}{r}21 \\
1\end{array}$ & $\begin{array}{r}48 \\
2\end{array}$ \\
\hline Total & 48 & 29 & 53 & 130 \\
\hline
\end{tabular}

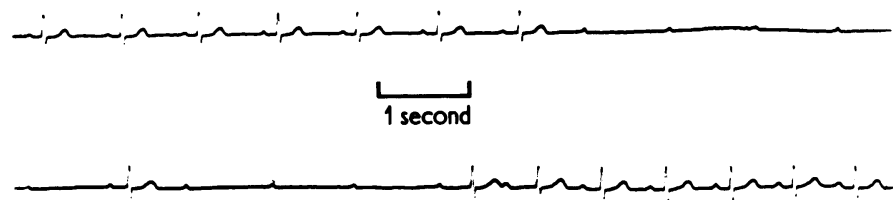

FIG 1-One of six episodes of complete heart block recorded on a single 24hour tape from a woman aged 47 who presented with dizzy turns. Her ECG was normal at rest and after exercise. Tracing shows sudden prolongation of P-R interval followed immediately by cessation of ventricular activity. There was one conducted beat during the period of arrest, and when ventricular activity started again the P-R interval gradually shortened until it was normal. Pacemaker was inserted with complete abolition of symptoms.
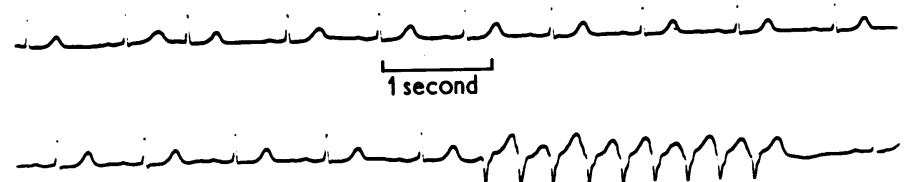

FIG 2-Isolated episode of ventricular tachycardia in a 70-year-old woman who presented with dizzy turns. Note junctional ectopic beat near beginning of the record.
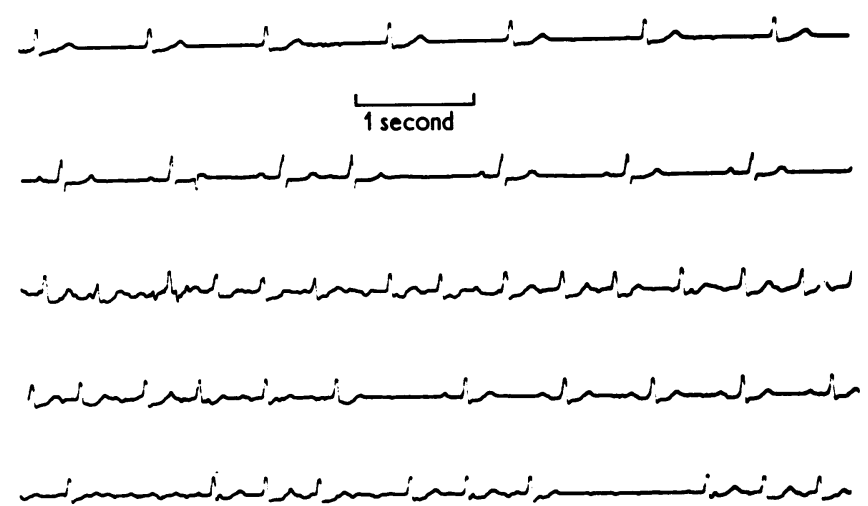

FIG 3-Five strips from single 24-hour tape showing junctional rhythm, sinus rhythm with junctional ectopic beats, rapid atrial fibrillation, reversion to sinus rhythm, and atrial fibrillation with "ventricular gaps" of $1.5 \mathrm{~s}$ in 62-year-old woman who presented with palpitations.

"Ventricular gaps" were seen in 26 patients and in 12 these were longer than 2.0 seconds. Six of these had a normal resting ECG. The gaps were seen against a background of atrial flutter or fibrillation 
in four, and were episodes of sinus arrest in eight (figs 3, 4, and 5). Fifty-seven patients showed episodes of supraventricular tachycardia: 26 complained of palpitation only, 17 of dizzy turns, and 14 of syncope. Episodes of atrial flutter or fibrillation were observed in only eight patients, of whom five complained of syncope. Significant numbers of ventricular ectopic beats were seen in 39 patients who were evenly distributed among the three symptom groups. No episodes of ventricular fibrillation were observed.
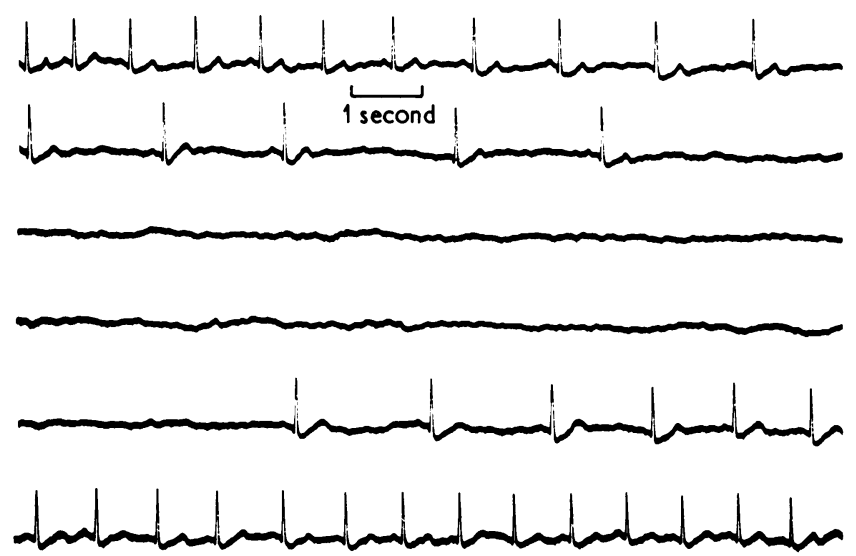

FIG 4-Continuous record of ECG during sleep in 65-year-old patient complaining of dizzy turns. Note slowing of heart followed by $30-\mathrm{s}$ period of asystole before sinus rhythm was restored.

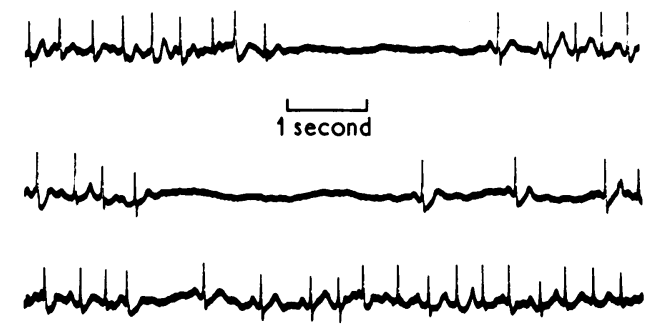

FIG 5-Continuous record of ECG in 69-year-old patient complaining of blackouts. Tracing shows bouts of rapid atrial flutter/fibrillation terminating in asystolic periods and followed by sinus beats, which revert to flutter/ fibrillation again.

Very few of the patients in this study showed a single dysrhythmia. The tape recordings usually showed a mixture of different supraventricular and ventricular dysrhythmias. We repeated 84 tapes and 26 showed dysrhythmias not previously identified. They included tapes from one patient who had five tapes that were entirely normal, two that showed episodes of ventricular ectopic beats, and two that showed episodes of atrial fibrillation with long ventricular gaps.

Fifty-seven of these patients had exercise ECGs which failed to show any dysrhythmias, while only occasional ectopic beats were shown in seven. The tape recordings of these patients showed significant dysrhythmic episodes in 49 patients, including one with ventricular tachycardia and one with complete heart block.

\section{Discussion}

Patients presenting with transient cerebral ischaemic episodes or palpitation form a large problem in clinical practice. They often undergo exhaustive neurological investigations or prolonged residence in hospital awaiting an eye-witness account of an attack. More often the patient is regarded as neurotic and given a tranquilliser with no effect. We have used a small portable tape recorder with an amplifier to record ECG events to study these patients over long periods. The recordings are replayed at rapid speed and dysrhythmias detected automatically. Within 24 hours we can sample 100000 to 250000 heart beats as opposed to the 40-60 recorded on a standard 12-lead ECG.

The patients reported here all had symptoms but no abnormal physical signs. The 12-lead ECG was completely normal in 68 and showed ischaemic changes without dysrhythmias in 27. Long-term taping showed dysrhythmias which were considered to be sufficient to produce their symptoms in $74 \%$. It might be argued that the same incidence of dysrhythmias would be found in any population sample of the same age and sex as these symptomatic patients. But a study of sixty asymptomatic subjects in six decades from the ages of 20 upwards failed to show any dysrhythmias in $95 \%$, and important dysrhythmias such as supraventricular tachycardia in only $1 \%{ }^{6}$ Hinkle et $a l,{ }^{2}$ found a high incidence of dysrhythmias in a sample of 49 middle-aged men and related these closely to evidence of co-existing coronary artery disease. The subjects in their study, however, were confined to hospital and exposed to several stressful incidents throughout a six-hour period of recording, unlike our patients who were free to go about their normal activities. In these patients we were satisfied that the dysrhythmias were frequent enough and severe enough to be responsible for the symptoms. Attempts to establish a temporal relationship were not satisfactory because of technical difficulties. Diarykeeping was not easy for these patients and many of the observed dysrhythmias occurred during sleep, but it was clear from the few patients who kept adequate diaries that symptoms coincided with the more severe dysrhythmia episodes. There was no consistent relationship between the type of symptom and the individual dysrhythmias, except for ventricular tachycardia, which was particularly associated with palpitation.

Two-thirds of our patients were women, and all seven ventricular tachycardia recordings were in middle-aged women. This suggests that some of the symptoms commonly attributed to the menopause may be related to unobserved cardiac dysrhythmias.

Exercise testing may show dysrhythmias in a high proportion of patients without recourse to relatively expensive long-term recording systems. ${ }^{7}$ Nevertheless, this did not show any important dysrhythmias at all in our patients, in contrast to the long-term recordings.

The length of recording may have to be prolonged to detect paroxysmal dysrhythmias. A further significant dysrhythmia was observed in $31 \%$ of those patients in whom the recordings were prolonged beyond 24 hours. We suggest that a single 24hour tape should be performed first with the understanding that it should be repeated for up to three days if the first tape analysis shows nothing of any consequence.

\section{References}

1 MacAllen, P M, and Marshall, J, Lancet, 1973, 2, 1212.

2 Hinkle, L E, Carver, S T, and Stevens, M, American fournal of Cardiology, 1969, 24, 629.

3 Bleifer, S B, et al, Progress in Cardiovascular Disease, 1974, 16, 569.

4 Crook, B R M, et al, British Heart fournal, 1974, 35, 1009.

${ }^{5}$ Cashman, P M M, and Stott, F D, Biomedical Engineering, 1974, 54.

${ }^{6}$ Raftery, E B, and Cashman, P M M, Postgraduate Medical fournal, (in press).

${ }^{7}$ Lown, B, and Jelinek, H V, Progress in Cardiovascular Research, 1974, 16, 497.

Most tables giving height and weight for adults show increasing weights for increasing age. Ideally should one allow one's weight to increase slightly with age?

There is no physiological reason why adults' body weight should increase with age. This may happen because of adding adipose tissue, unless muscle mass is being increased by weight lifting or other strenuous exercise. It is probably better for men not to increase adipose tissue at any stage: modest fluctuations in adipose tissue in women may have little medical significance. Body weight should probably ideally show a slight decrease with ageing, since small but appreciable losses of skeletal and muscle masses usually occur from the age of 50 onwards. Indeed, some physically active well-muscled populations with adequate nutrition-for example, in New Guineashow these small reductions in body weight as ageing progresses in adulthood. 